\title{
Стратегия комплексного инновационного управления перспективным энерго- и ресурсопотреблением предприятия (на примере ОАО «Магнитогорский металлургический комбинат»)
}

Аннотация. В настоящее время экономическое развитие весьма нестабильно в соответствии с уровнем инфляции и современным состоянием мирового экономического сообщества в условиях пандемии коронавирусной инфекции, проблематика, затрагивающая энергоэффективность, остается актуальной. В данной работе проведен анализ действующей модели стратегии инновационного развития одного из ведущих металлургических предприятий нашей страны - это ОАО «Магнитогорский металлургический комбинат». Исследование перспективной организационной стратегии инновационного управления энерго- и ресурсопотреблением одного из крупнейших металлургических предприятий показал, что она основана на принципах устойчивого развития, а её основная цель - создание и обеспечение значимой ценности для сторон, которые заинтересованы в дальнейшем функционировании производственного комплекса.

Ключевые слова: стратегия управления, инновационное управление, промышленное предприяте, энергоэффективность, энергопотребление, ресурсопотребление, производство, планирование, промышленность.

Развитие экономики современного мира диктует новые правила в организации менеджмента предприятий и производств. Границы действия организаций определяются строго в соответствии с диктуемой, специально разработанной политикой в отношении рынка, межведомственных взаимодействий и собственного энерго- и ресурсопотребления. Сюда можно отнести правила (устав предприятия), основной задачей которых является разрешение спорных, конфликтных ситуаций, которые возникают на пути решения определённых производственных и коммерческих задач. Однако данные директивы являются достаточно узкими в вопросе управления тем или иным производством. Более влиятельной формой в этом случае можно назвать программы развития, на которые будет делать упор руководство для достижения крупных целей путём решения нескольких последовательных задач пошагово. Иными словами такие программы необходимы для реализации стоящих перед компанией задач и планов в рамках установленной политики [6].

Самая глобальная форма управления предприятием - это стратегия. Стратегией называется эффективный комплекс решений, которые определяют общий путь становления и эволюции компании [2]. Эта форма обеспечивает движение и жизнь 
предприятия с учётом влияния и прогнозирования событий различной направленности, которые могут оказать сильное влияние на эффективность его общей работы. Она интегрируется и внедряется для функционирования в соответствии с его видом деятельности. Стратегическое планирование решает вопрос реализации целей, которых хочет добиться производственный комплекс в современных меняющихся, контролируемых и неконтролируемых условиях социума, экономики на уровне страны и мирового сообщества как по стабильному пути, так и в условиях крайней неопределённости перечисленных сфер [5]. Исследования моделей развития предприятий, функционирующих сегодня на территории России, позволяют прийти к мнению, что общая эффективность работы и социально-экономических отношений требует разработки общенациональной стратегии [1].

Повышение конкуренции для промышленных производств является основным стимулом к актуализации и запуску оптимизационных процессов использования ресурсной базы [3]. Сюда относится энергопотребление и ресурсопотребление [3]. Так как экономическое развитие весьма нестабильно в соответствии с уровнем инфляции и современным состоянием мирового экономического сообщества в условиях пандемии коронавирусной инфекции, проблематика, затрагивающая энергоэффективность, остается актуальной.

Анализ долговременного эффективного энерго- и ресурсопотребления удобнее всего показать на действующей модели стратегии развития одного из ведущих металлургических предприятий нашей страны - это ОАО «Магнитогорский металлургический комбинат». Действующая и разработанная долгосрочная стратегия развития и управления этим предприятием затрагивает специфические зоны хозяйствования, их взаимодействие, окружение и интегрирование. Основные цели и ценности стратегии ОАО «ММК»:

- производство и поставка потребительской группе высококачественной продукции:

- создание ценности для всех заинтересованных категорий с помощью достижения качественных результатов во всех видах деятельности;

- максимальное удовлетворение запросов потребителей;

- современные стандарты в области экологии, охраны труда и окружающей среды;

- непрерывное развитие компании и производства;

- безопасная производственная среда;

- с социальная и экологическая ответственность.

Рассмотрим подробнее, как происходит стратегическое комплексное инновационное управление энерго- и ресурсопотреблением на ОАО «ММК», опираясь на 
аналитические направления, факты и актуальные цифры публичного интегрированного годового отчёта за 2020 год.

Энергопотребление и его эффективность рассчитываются с помощью мер экономико-энергетического анализа. Он включает в себя комплекс следующих последовательных мер: идентификацию используемых энергоресурсов в производственных процессах (электричество, вода, топливо и другие), анализ их использования в подразделениях предприятия, анализ эффективности использования каждого ресурса по отдельности и в целом. По итогам проводится анализ резервов энергосбережения с учётом современных тенденций, экологической политики и эффективности.

Ключевой показатель энергоэффективности - энергоёмкость производства. Она рассчитывается как удельный ресурсный расход на изготовление одной единицы продукции:

$$
\ni_{\mathrm{e}}=\frac{Q e}{T P}
$$

где Эе - энергоемкость продукции, кВт·ч (или кДж) / единицу продукции;

$\mathrm{QE}$ - затраченная энергия на производство всей продукции, кВт•ч (или кДж);

ТР - объем выпущенной за отчетный период продукции.

Энергоёмкость ОАО «ММК» за 2020 год составила 5,23 Гкал/т стали (21,9 ГДж/т стали). Её расчёт производился по методу сквозного энергетического анализа, рекомендованного Международным институтом чугуна и стали (Брюссель). Энергоёмкость с 2018 по 2020 гг. представлена на диаграмме:

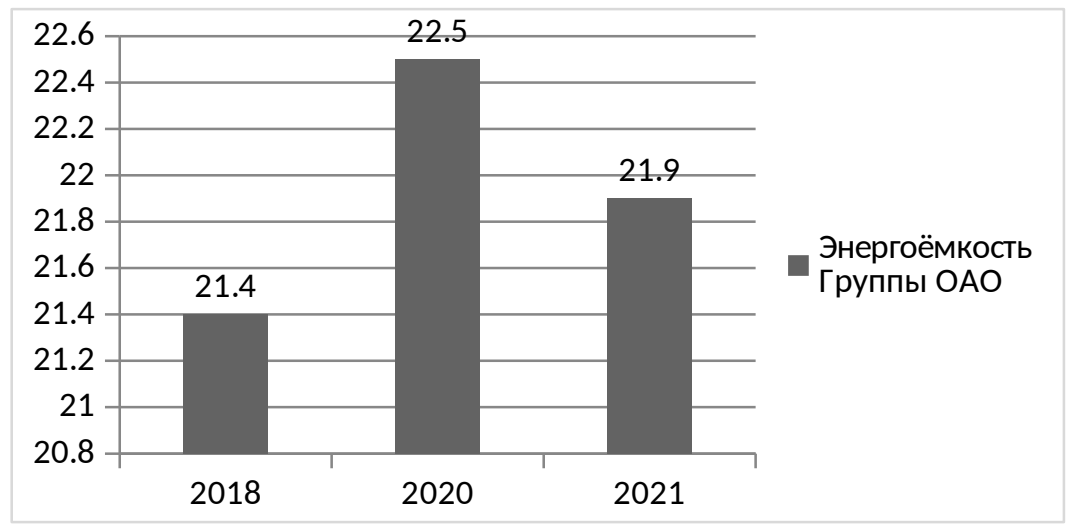

Рис.1. Энергоёмкость Группы ОАО «ММК» за отчётный период 2018-2020 гг.

На рисунке 1 видно, что стратегия инновационного управления энергопотреблением обеспечивает снижение показателя с 2019 по 2020 год практически 
до показателя уровня 2018 года. Результаты достигнуты без сокращения объёмов производства.

Ресурсопотребление - собирательная характеристика предприятия, которая представляет собой комплекс использованных (целевое или естественное) видов ресурсов (основной объём ресурсной базы направлен на производство) и их общее количество. Ресурсопотребление на ОАО «ММК» рассмотрим на примере водопотребления. Годовой отчёт комбината предоставляет следующие данные по безвозвратному водопотреблению:

1) 2019 год - 93922 мегалитров;

2) 2020 год - 91954 мегалитров [4].

За отчётный период благодаря эффективности управленческой стратегии объемы безвозвратного водопотребления снизились на 1968 мегалитров. Планируется сократить общий водозабор Группы компаний комбината из Магнитогорского водохранилища с 127500 мегалитров до 123700 мегалитров в 2021 году. Вместе с этим предприятие в целях устойчивого развития соблюдает экологическое законодательство и использует водные ресурсы повторно. По оборотному водоснабжению в Группе компаний эти показатели достигли 97,2\%. Общее оборотное водоснабжение представлено на рисунке 2:

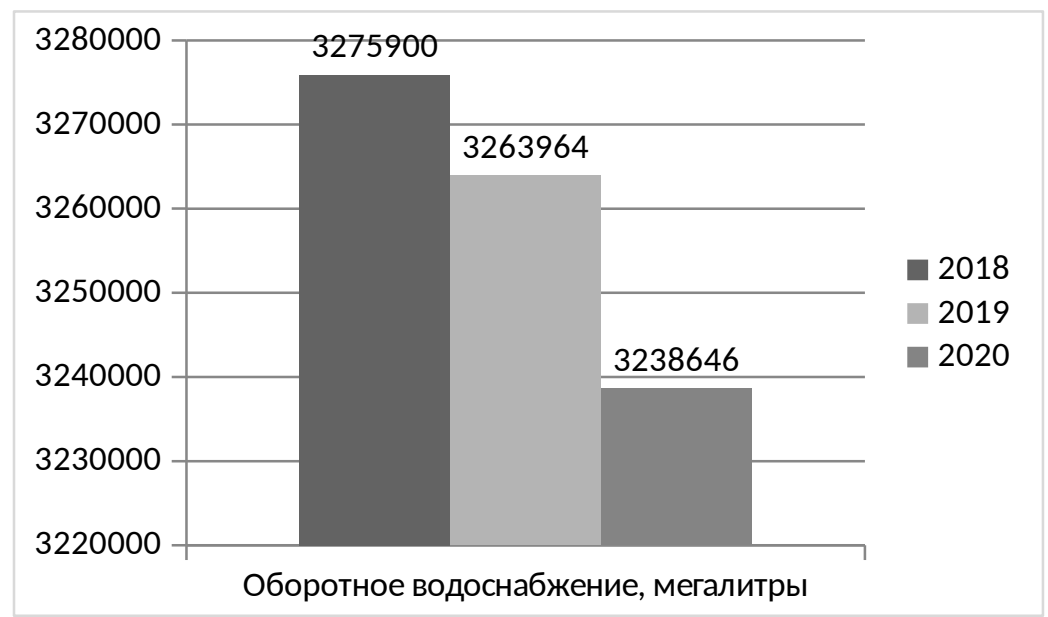

Рис.2. Оборотное водоснабжение Группы компаний ОАО «ММК».

Диаграмма показывает ежегодное снижение водопотребления. Объёмы производства чугуна и стали при этом не уменьшились, в 2020 году сохранилась доля премиум-продукции на прежнем уровне в 100\%.

Благодаря эффективной стратегии комплексным инновационным управлением энерго- и ресурсопотреблением Группа компаний ОАО «ММК» достигла также следующих производственных показателей (в том числе оказывающих негативное влияние на окружающую среду):

- Комплексный индекс загрязнения с 2017 по 2020 год снизился на 60\%;

- Валовые выбросы парниковых газов сокращены на 6,8\%; 
- Общий объём потребления электроэнергии по Группе снизился на 3,1\%;

- Объёмы отходов по Группе снизились на 28,4\%.

Стратегическое инновационное управление - важная составляющая любого предприятия, которое хочет оставаться эффективным, современным и конкурентоспособным на экономическом рынке, которое ориентирует свою инновационную деятельность на текущие запросы потребителей. Его значимость состоит в том, что именно оно является определяющим фактором жизнеспособности и развития всего производственного комплекса. Анализ перспективной организационной стратегии управления энерго- и ресурсопотреблением одного из крупнейших металлургических предприятий - «Магнитогорского металлургического комбината» показал, что она основана на принципах устойчивого развития, а её основная цель - создание и обеспечение значимой ценности для сторон, которые заинтересованы в дальнейшем функционировании производственного комплекса [4]. Разработанная и представленная руководством новая стратегия данного комбината (до 2025 года) предусматривает повышение операционной и функциональной бизнес-эффективности без расширения общих объёмов производства, снижением влияния деятельности Группы на окружающую среду и с сохранением объёмов производства премиальной продукции Группы ОАО «MMК» (100\%) . Это позволяет предположить, что стратегия обеспечит стабильность взаимодействия всех структурных частей в соответствии с установленными объёмами энерго- и ресурсопотребления и оставит их показатели на том же уровне.

\section{Список литературы}

1. Агафонов, В.А. Стратегический менеджмент. Модели и процедуры: Монография / В.А. Агафонов. - М.: Инфра-М, 2019. - 350 с.

2. Айдаркина, Е. Е. Теория и практика управления: учебное пособие / Е. Е. Айдаркина ; Южный федеральный университет. - Ростов-на-Дону ; Таганрог : Издательство Южного федерального университета, 2020. - 164 с.

3. Грушенко, В. И. Менеждмент. Восприятие сущности менеджмента в условиях стратегических изменений: учебное пособие / В. И. Грушенко. - Москва : ИНФРА-М, 2019. - 288 c.

4. Годовой отчёт Магнитогорского металлургического комбината за 2020 год; Магнитогорск, 2021. - 125 с.

5. Котлер, Ф. Стратегический менеджмент по Котлеру: Лучшие приемы и методы. / Ф. Котлер. - М.: Альпина Паблишер, 2016. - 132 с. 
6. Логиновский, О. В., Голлай, А. В., Дранко, О. И. [и др.] Эффективное управление организационными и производственными структурами: монография /; под ред. О. В. Логиновского. - Москва: ИНФРА-М, 2020. - 450 с. 